\title{
XII. ON THE CONTRIBUTION OF THE MOST RECENT RESEARCH ON LANGUAGE APPLIED TO PSYCHOANALYTIC PRACTICE
}

\author{
JORGE CANESTRI
}

The fact that analytical practice, named the "talking cure", as well as the theory on which it is based, has to come to terms with language and the various disciplines that deal with it, may appear to be a truism. However, in psychoanalysis this confrontation is not treated with the necessary solicitude or awareness. Even less frequently do the linguistic disciplines take an interest in the psychoanalytical insights on the nature and functioning of the psychic apparatus, or consider the exquisite peculiarity of clinical experience as a possible area of research.

The objective of this brief paper, in which I will try to take some regional differences into account, is to give an overview of the problems that recent research in the vast field of work on language put to psychoanalysis. It would obviously be possible to reverse the perspective and consider the problems identified as being an input to research methodology in the disciplines mentioned above. I should like to clarify that I am speaking about research on language and not about linguistics, because in this research linguistics are certainly present, but so are the neurosciences, psycholinguistics, philosophy of language, semiotics, etc.

The relationship between psychoanalysis and research on language may be approached by referring to the psychoanalytical works that have attempted to present a critical, theoretical and historical survey. This also allows us an intuition into the regional differences. In general, the object of these works is mainly the relationship between psychoanalysis and the theory of linguistics in the strict sense. I will mention three works in particular from three different regions (North America, Latin America and Europe) because they clearly illustrate the differences in formulating the problem.

The first is the well known paper by B.E. Litowitz and N. Litowitz (1977) published in the Journal of the American Psychoanalytic Association, "The influence of linguistic theory on psychoanalysis. A critical, historical survey". The title reveals that in this work also the direction of the reading is from linguistics to psychoanalysis and not vice versa. The authors are aware of this when they write: "In addressing the topic of the influences of psychoanalysis as an intellectual system upon linguistics as the systematic study of language we are viewing a subject 
with little, if any, past, some present and an open, hopeful future" (p. 419). Undoubtedly, this is one of the clearest and most complete works as far as formulation, identification of problems, and linguistic competence are concerned. In it are identified "three major shifts in linguistic theory (labeled nineteenth-century, modern and recent)" and an attempt is made to explain the reasons and advantages for each shift. The authors inform us that "Following each description, psychoanalysts will be grouped as having been influenced by one or another of the major linguistic theories" (p. 419). The list of the authors and their corresponding works is very complete regarding English-speaking psychoanalysts, and it surprisingly also includes a very relevant author from Latin America who has not been translated into English and who belongs to the last shift described in the paper (recent, Chomskian-oriented linguistics): I am talking about David Liberman (1983). Among the French-speaking psychoanalysts the "linguistic" concepts of J. Lacan are carefully analyzed and A. Green is mentioned, but not his works that are more specifically dedicated to the relationship between language and psychoanalysis. There is no reference to German-speaking authors except for the philosopher Habermas. I mention these aspects about which thinkers are taken into consideration and which are not, because it helps to understand the regional differences. The work mentioned above was written in 1977, and although it is one of the most complete, it is certainly outdated. "Recent" linguistics goes as far as the most classical theories of Chomskian generative grammar, already abandoned by the American linguist, while the current generative linguistics is dominated by two strands: a) the Theory of "Principles and Parameters" (Knowledge of Language 1986) and "Minimalism" (The Minimalist Program, 1995).

If, on the other hand, we consider the work of authors from Latin America, besides the use of important linguistic theories we also note in them a careful examination of the bibliography relative to the relationship between psychoanalysis and language in other idioms (English, French and German), but with little interest in the North American psychoanalytical bibliography on this theme. I quote a paper by Susana Vinocur de Fischbein (1998): "Psicoanálisis y lingüística: contactos e intercambios" (Psychoanalysis and linguistics: contacts and interchanges), that, besides offering a review of the relationship between linguistics and psychoanalysis and a summary of the Latin American position on the matter, also inquires into present day linguistics and suggests some possible areas of research. The author underlines the fact that linguistics has shown its influence on three different areas of ana- 
lytical theory and practice: a) one that could be called 'psychoanalytical psycholinguistics', comprising the theory of symbol formation, of the symbolic processes in general, and of the acquisition of language; $b$ ) another that attempts to individuate the role of language in the structurization of psychism: language as a function and/or psychic structure, c) the third is the area regarding the meaning of language in clinical practice. She analyzes some of the most interesting aspects of contemporary research on language, for instance pragmatics, intertextuality, inferential pragmatics and its theory of implicature (Grice) or of relevance (Sperber and Wilson) and the discourse analysis. From this point of view, her work, although in terms of historical and critical aspects considerably less exhaustive than the previously mentioned work, is much more in agreement with the most recent research.

Turning now to the European region, the choice of a representative work becomes more complex: firstly because there are no summarizing papers similar that of Litowitz; and secondly because they are strongly characterized by theoretical standpoints that are usually clearly defined and even polemical. The panorama ranges from Lacan's 'linguisterie' to Lorenzer's hermeneutics. Perhaps the most relevant aspect of the European formulation of the linguistics-psychoanalysis relationship is the fact that the emphasis is always on psychoanalytical metapsychology, in other words on the requisites that a linguistic theory must have in order to be compatible with psychoanalysis. If this is not so, then the linguistic theory can be deformed (Lacan's linguisterie) or not taken into consideration.

A book that I could quote is by the French linguist and psychoanalyst L. Danon-Boileau, Le sujet de l'énonciation (1987), in which the author outlines the field of linguistics-psychoanalysis interaction following the classical divisions of the Freudian model: economic, dynamic, topical and 'genetic'. In this framework every psychoanalyst (mainly French and some well-known English analysts such as Winnicott, Bion and Segal) finds a place. Litowitz did something similar when she compiled a classification of the authors according to the influence that the linguistic theories had had on them.

Another significant text seen from a very different viewpoint is the well-known "Le langage dans la psychanalyse", by A. Green (1983). In it, as well as in a subsequent work "Le langage au sein d'une théorie générale de la représentation" (1997), he sets out the conditions that a theory on language must comply with in order to be acceptable to psychoanalysis. Perhaps, as we shall see later, Green's major contribution 
to the linguistics-psychoanalysis relationship is the general theory of representation.

Although looking at the issue of the relationship between psychoanalysis and research on language from the point of view of the above mentioned works can give a rough idea of the differences between the regions, it does not offer an adequate outlook on the problem in general. It could be better defined through an accurate analysis of some of the problems that linguistic models present when the analytical experience has to be taken into account. A minimum outline of the relevant concepts in the field of research on language that might weigh on psychoanalytical practice and theory should include:

1. Philosophy of language: the change of the classical, propositional paradigm (semantic-logical-referential) with a pragmatic, dialogical one. Pragmatics and its importance as performance theory at the semantic level. The inferential pragmatics and its theory of implicature (Grice) or of relevance (Sperber and Wilson) and its influence in clinical practice.

2. Discourse analysis.

3. Rules of transformation in listening and interpretation.

4. Acquisition of language. Biological bases of language, neural plasticity, research in neurosciences. Early interactions, pathological dyads. Inner language, language of thought, language and thought.

5. General theory of representation.

I will very briefly try to illustrate these issues:

\section{PHILOSOPHY OF LANGUAGE}

To explain the meaning of the change of the classical paradigm in a new one I have used, in a chapter of the book Changing Ideas in a Changing World (Canestri 2000), an anecdote that the German philosopher Karl Otto Apel proposes at the beginning of his book Le Logos propre au langage humain (1986). I repeat it here because I think it clearly illustrates the problem of the two paradigms of the philosophy of language. Karl Otto Apel recalls that his reflections were suggested to him by a comment of Karl Popper. Following a lecture of Apel's in which the philosopher attempted to outline the program of a pragmatictranscendental theory of communication, Popper said that it is not necessary to pay so much attention to communication inasmuch as it is what we have in common with animals, and that what is important in human language are the propositions. This comment sums up the prob- 
lem perfectly. Popper very precisely defined the classical paradigm that from Aristotle to Frege informs the philosophy of language. "The classical or propositional paradigm to which Popper refers, is the semanticlogical-referential of the logos. As Apel reminds us, the platonic root of logos, on the other hand, was dialogic: logos as language and discourse in conversation. From the viewpoint of the classical paradigm there would be a division and an opposition between referential semantics and simple pragmatics of the communicative functions of language. The classical paradigm does not consider that pragmatics contributes to the semantic logos, to the inter-subjectively valid meaning of the signs of language and to the meaning of theories. A conception of linguistic activity that does not recognize the contribution of pragmatics to the construction of the meaning, that is, its semantic contribution, would be extremely limiting in analytic practice and would contradict our experience" (Canestri 2000, pp. 198-9).

Probably no psychoanalyst in his clinical practice has ever neglected this aspect relative to the contribution of pragmatics in the construction of the meaning, inasmuch as Freud, in the third chapter of his rightly famous book Jokes and their Relation to the Unconscious, proposes the well known joke: "Two Jews met in a railway carriage at a station in Galicia. 'Where are you going?' asked one. 'To Cracow', was the answer. 'What a liar you are!' broke out the other. 'If you say you're going to Cracow, you want me to believe you're going to Lemberg. But I know that in fact you're going to Cracow. So why are you lying to me?" The following comment by Freud anticipates several of the above mentioned issues. He writes: "But the more serious substance of the joke is the problem of what determines the truth [...] Is it the truth if we describe things as they are without troubling to consider how our hearer will understand what we say? Or is this only jesuitical truth, and does not genuine truth consist in taking the hearer into account and giving him a faithful picture of our own knowledge" (1905c, p. 115). This excellent example certainly gives us food for thought, as Freud himself notes. But what I wish to emphasize in this case is the fact that Freud places pragmatics in the foreground; in fact, in the communication between the two Jews, the truth does not depend on the description of "things as they are", but on what the subjects do with the words (Canestri 1999a).

Certainly, applying an implicit knowledge of the function of pragmatics in the construction of the meaning in clinical practice, is not the same as working and carrying out systematic research in this perspec- 
tive. In the three regions mentioned there are some analytical works that take these principles into consideration. I can mention the already quoted S. Vinocur de Fischbein (1998) in Argentina, T. Shapiro (1988, 1991) in the U.S.A., L. Danon-Boileau (1987) and myself in Europe, and I could list many other names from every region.

\section{DISCOURSE ANALYSIS ${ }^{1}$}

Putting the accent on the linguistic production of the individual rather than on the ideality of the language, favours the growth of an area of research entitled "analysis of the discourse", which privileges the structure of spoken language as manifested in current use: conversation, interviews, etc. The 'discourse' is opposed to the 'langue' (language, because we have no other word in English to name the French opposition between 'langue' and 'parole') since it implies the use of the 'langue' in a certain context. As Charaudeau and Maingueneau (2002) point out, the proliferation of the term discourse in the sciences of language "is a symptom of a modification in the manner of conceiving language" (p. 187). Language is studied as a dynamic, social, intersubjective phenomenon, intrinsically dialogic, in the original meaning of platonic "logos" (mentioned before) or in the more recent meaning resulting from the studies of Mikhail M. Bakhtin. It is possible to make a typology of discourse, and to describe some of its defining characteristics: to be a form of action, to be contextualized and interactive, etc. A first field of research for psychoanalysis would be the description and careful study of the specific characteristics of the psychoanalytic discourse (which could be conceived as a particular type of discourse) that is so profoundly different in rules, structure and codification from any other discourse of ordinary communication. To offer a few examples: the endofasic internal discourse of patient and analyst, that elsewhere I have called "internal flux" (Canestri 1994a), does not have to take pragmatics into account, but pragmatics reappears in the uttered sentences of both. Nevertheless, the existence of the fundamental rule of free association and free floating attention allows both participants of the experience to transgress canonical rules in the analytic communication. In analysis the word expresses the drive and is also a drive object that must be interpreted (Fónagy 1983); there are a great many envel-

${ }^{1}$ This paragraph is a re-elaboration of some of my previous works (Canestri 1999a, 2000). 
oped registers (preverbal, organic, paralinguistic), conditioned in their turn by the context (internal transcriptions, transmutations of code, etc).

The analysis of the discourse brings to the forefront the production of utterances. The different forms that the presence of this act of production can take, and also the degrees of its importance, enable a specific typology of the discourses to be created. From the point of view of the analytic discourse, the study of the elements of the utterance that allude to its production is particularly significant because they are part of the actual sense of the utterance. Some of these allusions are represented by grammatical categories such as personal or demonstrative pronouns, relative adverbs and adjectives or tenses of verbs (i.e. deictic categories); other allusions are represented by semantic categories such as the time and the place of the utterance.

In the follow-up of the analytic process we can obtain a great amount of knowledge about psychic change by analyzing the discourse of the patient. This implies considering to whom the patient speaks (transference) and how he perceives himself, not only through the analysis of the content of his unconscious fantasies. It is important also to observe the linguistic means that he uses (and that are normally unknown to the speaker), e.g. personal pronouns, to represent all this in the discourse. Within this vast field of research I should mention the work of the psychoanalyst and linguist L. Danon-Boileau (1987) (France) in that, as a disciple of Antoine Culioli, he proposes a "linguistics of the utterance" that he considers could be particularly useful in the analysis of the psychoanalytic discourse. Certainly, many others could be quoted, and with many different theoretical orientations ranging from those who do simple computer-assisted analysis of lexical frequency to those who, like E. Mergenthaler and W. Bucci propose an interpretation of the referential process in the psychotherapeutic discourse context by computer assisted text analysis (1998).

\section{RULES OF TRANSFORMATION IN LISTENING AND INTERPRETATION ${ }^{2}$}

In the linguistic activity of individuals, language becomes a complex and heterogeneous object. All the more so in the analytic discourse where the three classical channels described by semiotics are co-present

${ }^{2}$ In this paragraph I re-elaborate some ideas I discussed in previous works (1994a, 1994b, 1999a, 2000). 
and cannot be dis-articulated. I refer to the first channel of articulation (segmental) that includes, in order of increasing complexity, phonology, morphology, syntax and stylistics; a second channel (or supersegmental level) that includes a wide range of phenomena coming under the classification of prosody (tone, accents, pauses, silences, intonation and expressive connotations); and a third channel or level including non-verbal elements such as gestures, facial mimicry, movements and positions of the body, etc. If we can say that the activity of the analyst relies to a large extent on his/her capacity to contain and adequately transform the unbearable experiences of the patient through a correct de-codification of the patient's communications then the importance of a conception that takes into account the complexity of the individual's linguistic activity and of the whole range of semiotic systems both for production and for recognition, becomes all the more evident.

It is necessary to carefully reflect on the meaning of a process that is frequently formulated as an identity: "to decode, that is, to interpret" and also on the nature of the transformational rules in it. Keeping within the area that I have tried to define, I think that the work of H. P. Grice (1989) can be of assistance to us. Grice formed part of the Austin group, and after the rejection of neo-positivism that lead the "Oxford Philosophy" to abandon all types of formalization, he was the one who, in the field of the philosophy of language, was able to develop theories. Here I should like to mention just four very important distinctions introduced by Grice: (a) between the natural meaning and the non-natural meaning; (b) between what the words mean and what the speakers mean; (c) between what is "said" and what is only "implied", and (d) between the conventional meaning and the non-conventional meaning.

Grice tries to explain what a single speaker in a given circumstance means by a word or a gesture. It is this concept of meaning, that Grice calls "the meaning of the speaker", that precedes the concept of the linguistic meaning and not vice-versa. It is not the conceptof conventionality (distinction between natural signs and conventional signs) that distinguishes the non-natural meaning from the natural meaning, but the concept of intentionality (connection between meaning and intentions, between semantics and psychology). If I mean something, I must intend to obtain a given effect on my interlocutor, at least in part through his recognizing my intentions. This is where a vast field of possibilities opens up from the psychoanalytical viewpoint. The intentionality that concerns us as psychoanalysts is not the conscious one; the effect that a patient tries to obtain does not correspond to a conscious but to an un- 
conscious wish (and a good example could be the way projective identification operates). In Grice's theory the meaning of a sentence ultimately depends on what the speakers mean when they utter it, as long as the linguistic use is correct. When we converse, we often mean more than what the words mean literally, or we mean something different from their literal meaning. Grice here introduced the concept of "implicature"; the "implicature" has the task of systematically linking what is said to what is implied, therefore explaining how it is possible to do what we do continually when speaking, i.e. communicating more than our words mean literally. A corollary of this statement is that a proposition is certainly conveyed by an utterance, but this depends not only on the utterance pronounced, but also on the circumstances of the utterance and on a series of general rules governing the conversation and the use of the language.

Comparing Grices' ideas with those of Davidson (1984) on similar issues is very interesting. Davidson postulates that in order to understand the meaning of an utterance it is necessary to insert the discourse into the general framework of rational action. He emphasizes that an utterance directed to an interlocutor is an action with two components: the wish to produce a reaction depending on the semantic characteristics of the utterance, and the belief that the interlocutor has the necessary resources to understand the utterance just as we ourselves intend it. Moreover, Davidson considers that during the course of the exchange we provide the other with a series of clues that help to orientate him.

Another step forward has been made by Sperber and Wilson (1986). The starting point of these authors is a reflection on the classic model that tries to explain how communication takes place. According to the classic model or code model, coding and decoding messages is communicating. Grice's theories (but also Davidson) suggest a different model, the inferential model, where communication consists of the production and interpretation of facts. These two models are not incompatible and can be combined in various ways. Verbal communication brings into play at the same time both inferential processes and codifying processes (as can be seen in Davidson's conceptualisation). A code is a system that associates messages with signals and requires a codifier and a decodifier. The inferential model must include central processes at the entrance and at the exit, a set similar to: thought processes $\rightarrow$ acoustic codified signal $\rightarrow$ acoustic signal received and de-codified $\rightarrow$ thought processes. From this point of view the semantic representation of a sentence does not coincide with the thoughts that can be communicated by 
pronouncing the sentence. We pass from semantic representation to communicated thought not through an addition to the code but by means of inferentials.

It is clear that the distinction between sentence and utterance is essential; an utterance possesses a set of characteristics, some of them are linguistic, others not. The study of the interpretation of utterances belongs to pragmatics, utterances express propositional attitudes, they carry out linguistic actions, or else they have "illocutionary force".

Summarizing, from this viewpoint, communication succeeds not only when the speakers recognize the linguistic meaning of the utterance, but also, and sometimes predominantly, when they infer the "meaning" of the utterer. It is worth reflecting on how and when this operates in psychoanalytic practice.

From the point of view previously illustrated (Grice, Davidson, Sperber \& Wilson) the patient as well as the analyst both "say more" than they are aware of. This is normal on the part of the patient and is, in a way, at the basis of the possibilities of our inferring and interpreting. Generally we are less aware that our interpretations also "say more" than they apparently do not say. After all, we are not always aware of the mechanisms that moderate our comprehension of the patients' material, and of how much of that comprehension we remain unaware of and yet is transported in the interpretation, not through its content but through its implications. Equally often the therapeutic quality of an intervention cannot be measured from the content itself of the interpretation, but from the implications that it contains. It is like saying that "we are doing well" without knowing it, i.e., that the "doing well" is frequently a quality in the analysts' unconscious that is explicated through his or her speech. This argument is closely linked to the discussion about the "therapeutic factors" in analysis. For lack of space I am unable to propose some clinical examples that would illustrate the type of deconstruction of the analytical dialogue that these concepts make possible. ${ }^{3}$

\section{ACQUISITION OF LANGUAGE}

We cannot discuss language - and even less so the relationships between sciences of language and psychoanalysis - without considering how language is acquired. Nor can we hide the fact that there is no ex-

\footnotetext{
${ }^{3}$ I proposed one in Canestri (1999b).
} 
planatory monolithic theory, while it can be said that the new techniques that study the emergency and consolidation of language have reached a high level of refinement and reliability, in many cases revolutionizing the knowledge that we possess.

I only want in this paper to underline those aspects that I think are linked to the psychoanalytical experience and that psychoanalysis must take into consideration. Probably it is the knowledge acquired through the use of new techniques that permits us to trace a new and perhaps median route between the two great families of theories that deal with the explanation of how children come to acquire language. The first of these two families privileges those linguistic constrictions that are considered innate (learnability theory, theory of Principles and Parameters, theories of bootstrapping); the second emphasizes the cognitive and communicative determinants of acquisition.

Each of these families, as they evolved in order to formulate theories more adherent to the data provided by experience, has in its turn created solutions including elements from the other family. Let us for example consider the evolution of the family of theories that privileges innateness. From the initial Chomskian position on the existence of a Language Acquisition Device, Chomsky himself moves on to the theory of Principles and Parameters that gives rise to the 'learnability theory' and to the idea that a suitable environment is only a trigger for the innate linguistic faculty (principle of 'I language'). However, also within this current of thought, this extreme position is modulated by the theories of 'bootstrapping' (syntactic, semantic and prosodic bootstrapping); Pinker (1987), for example, favors the intervention of non-linguistic capacities (perceptive and cognitive) that contribute to the acquisition. It is, however, fairly evident that the theories of this family do not take into account the psychological mechanisms that might intervene, or the factors linked to development, or the role of the environment beyond serving as a trigger. From the point of view of psychoanalysis, these theories, at least in their most radical versions, prove to be unsatisfactory since they do not answer any of the problems raised by clinical experience, also with very young children. They are just as unsatisfactory when considering childhood language pathologies. The experience of those specialists - neuropsychologists and child neuropsychiatrists - who treat them contradicts many of their basic hypotheses and is more in agreement with a neo-Piagetian type of cognitive hypotheses.

Communicative and cognitive theories on the acquisition of language present, in the same way as the previous ones, many versions and 
variations. The theory called interactionist, based on the linguistic theory of Austin and Searle of the Speech Acts, does not attribute to the child an initial language endowment, but it assigns to social exchanges the task of bringing the child to the construction of abstract linguistic units, of grammatical rules, etc. I think this version, that appears to be just as radical as the most radical innatist positions, is of particular interest concerning the pragmatic dimensions of language that I dealt with previously. It allows us to explore a dimension that is essential from the point of view of psychoanalysis and that is overlooked by other theories, i.e. the dimension of the effective and affective motherenvironment/child exchange and the constitution of more or less normal or pathological dyads. I shall return to this issue later on. However, it is clear that from the point of view of language acquisition as such, this theory leaves many questions unanswered.

The cognitive theories underline the need to link language and cognition and to thus hypothesize the existence of cognitive prerequisites in order for language development to be possible. There are many authors representing many modulations of this principle, but I mention only A. Gopnik (1997, 2000) and Karmiloff-Smith (1992). It is fairly evident that these theories are related to Piagetian cognitive models, although they attribute to the child many more inferential capacities than Piaget conceded to them; besides, this is in line with the development undergone by the School of Geneva. Research in this area has also stimulated the cross-linguistic studies of language acquisition and these have proved to be fundamental from many points of view.

Among the cognitive theories according to which language acquisition derives from a general cognitive base, perhaps the most interesting are those that use connectionist perspectives on development (the title of a book written in 1996 by Elman, Bates, Johnson, Karmiloff-Smith, Parisi and Plunkett) and place the accent on the non-linear development of auto-organized systems with successive modularization. To my mind, this perspective is interesting because it is nearer to certain facts evidenced by neuro-scientific research. Probably the moment has come when this research, made possible, as I have said, by the new exploratory techniques (essentially neuroimaging techniques), will help to construct a third family of theories more radicated in the data coming from our present knowledge about the biological bases of language and about cerebral organization, its plasticity and functional specialization relative to development. In the same sense, we must pay attention to the reeducative experiences of infantile language pathologies because they 
can provide data of great interest. The perspectives of this type of research are innumerable and the rhythm of the discoveries is in continual acceleration. To quote one example, in the issue of 18 October 2002 of Science an interdisciplinary and international team working at the Sissa in Trieste (Peña, Bonatti, Nespor \& Mehler 2002), using precise experimental methods, have shown how, very early on, a baby can distinguish in the continuous flow of spoken language (also when the researchers used an invented language) the end of one word from the beginning of the next. This is based on the possibility to make unconscious mental calculations that reveal statistical regularity, which is a computational aspect of the brain.

Many of the questions we have asked ourselves about the different aspects of language acquisition including, for example, very early bilingualism and the cerebral organization of two or more languages, today find convincing answers in the techniques of neuroimaging. Many of the hypotheses we formulated in the past before we had these techniques can now be confirmed or rejected with a high degree of certainty. For example, in the work carried out together with colleagues J. Amati Mehler and S. Argentieri (1993) on bi- or polylinguism in analytic practice, our theory on the hypothetical configuration of languages in the brain and on memory organization has been partly overtaken by more recent research using neuroimaging (cf. Fabbro 1999). Without this research, the mechanisms in question would remain unknown.

As research stands at the moment, it is reasonable to think that, in the cerebral organization of multilinguals, the representation of the mother tongue occurs through ways and processes that partially differ from those used for the representation of other subsequent languages. Within the mosaic of the memory systems, the acquisition of the mother tongue seems to be linked to the procedural memory, i.e. to an implicit mechanism that does not require awareness and that functions through repetition of the task, with the involvement of the sub-cortical structures connected to the prefrontal associative areas. Even if there is a partial overlapping of the areas involved in the use of languages that have been acquired during different periods of life, some anatomic and functional differences are noticeable in the group of "late bi-polylinguists" according to the language used from time to time (Paradis 1995; Fabbro 1999; Kim, Relkin, Lee \& Hirsch 1997).

Besides my clinical experience, the proved existence of dynamic rearrangements in the brain, even in an adult one, incline me towards a non-rigid and functional hypothesis of the "regulation of access" to the 
different representation systems. This is in agreement with the tendency place increasing importance on the cerebral plasticity, especially in very early infancy. This is also demonstrated in cases of extensive malformations of one hemisphere requiring early radical hemispherectomy where we can see how the right hemisphere almost completely takes over all the functions of the other hemisphere, privileging those higher functions that are essential from the adaptive point of view (Canestri 2000). Without insisting too much on this issue, from this example we are able to draw some conclusions about the innatist hypotheses that privilege excessively rigid regional localizations or specializations.

The same amount of attention should be paid to the aspects that are connected to the development of the entire linguistic system. While the phonological and syntactical aspects linked to the unaware procedural memory are already well developed before the age of three, in harmony with the advanced maturation of the competent nervous structures (basal ganglia, cerebellum, sensory-motor cortical areas), the lexical aspects of language come later, in correspondence with the later maturation of the nervous structures linked to the declarative memory (hippocampus and temporal-parietal areas). In the same way the auditive development and corresponding perception is much more rapid than the development of the phonatory articulation system (three months for the first against eighteen months for the second). Auditory reactions and recognition occur very early (even in the uterus and mainly concerning the mother's voice). Unlike the phonatory articulation system, the auditory system needs no practice and is a system that is specialized right from the start for accomplishing a sensorial function, while the phonatory system is the heir to a long adaptive history that has transformed a visceral system (pneumogastric nerves) into a system with a linguistic purpose (Hagège 1996). I mention these aspects in order to emphasize the importance that a careful consideration of the concurring elements, with different maturating times and modalities, can have in the development of the "linguistic system" in the child. From the psychoanalytical angle as well, it is impossible to overlook the fact that the moments of psychological development, which are so crucial in our discipline, play a significant role in determining the quality of the representations and of the words to which they are linked. I will briefly return to the role of pragmatics in language acquisition that I mentioned earlier.

A pertinent aspect in the study of linguistic development in the mono or bilingual child is certainly that of the "linguistic" exchange with the environment and, obviously in a privileged manner, with the 
mother. Putting "linguistic" in inverted comas indicates that this concept must be understood, in this case, in its widest sense and close to that of a "complex semiotic system", some of whose elements are strictly linguistic and others not. It is at this level that the learning of the "mother tongue" meets the primary relationship with the mother, even though the two must not be homologated. It would be misleading today to study language acquisition without mentioning the so-called "baby talk, motherese or child directed speech", i.e. without taking into consideration the ways in which we speak with babies.

I have intentionally emphasized with babies because, as Snow (1986) pertinently writes, mothers do not speak to babies but with them, in a manner that could be qualified as conversational (and in the very early phases of life as protoconversational) and that is governed by the child. The mother does not try to teach her child to speak, but tries to effectively communicate with him, and to do this she uses certain particular modalities that have been amply described, analyzed and discussed. What is important to consider is the fact that the learning processes perhaps differ in the different periods of the development of linguistic acquisition, that there are more or less efficacious processes of linguistic adaptation between adults and children, that there exist some pathological (non-answer of the mother to the child's expressions, answers that are unconnected and not semantically or affectively pertinent: intonation, modulation, rhythm, etc.) "dyadical constructions" (E. Lieven 1978) that in psychoanalysis we would consider as a consequence of the pathology of the mother-child relationship, and that the entire linguistic learning process is intimately linked to the affective "monitoring" between mother and child and more widely between child and environment. The "pathological dyadical constructions" do not seriously hinder the learning of language as such (at the most they could slow it down, favoring a language that is poor, repetitive, not very informative or difficult to interpret, consequently impoverishing the feedback and increasing the problem of communication), but it is evident that they can be at the root of many difficulties described in clinical cases and are psychoanalytically relevant. An increase of studies in this direction would be advisable. The simultaneous presence of several languages and the relationship that is installed with them in the child's primary environment could alternatively increase his creativity and affective-linguistic richness, or induce an additional pathology if the communication system is already pathological. This last eventuality, therefore, would not depend on the presence of several languages, as we 
have abundantly tried to demonstrate (Amati Mehler, Argentieri \& Canestri 1993), but on a defect of the system.

At the beginning of this paragraph, when speaking about linguistic exchange with the environment, I said that the word "linguistic" is to be understood in the sense of a complex semiotic system. This is justified not only because during linguistic interaction the child, until he is eighteen months old, is in a pre-linguistic phase (or pre-verbal, if you prefer), but also because linguistic communication is inseparable from gestural and motorial expressions, from prosodic levels and from the use of multiple channels of communication that are a part of the system: physical contact, glances, etc. Regarding this, it is enlightening to observe how the spontaneous construction of sign "languages" in deaf children follows the language acquisition programme.

The theme of affective mother/environment-child exchange has strong connections with what I have said above. Whatever the preferred psychoanalytical theory may be, we can all agree on the words of R. Pally (1998): "Emotion connects not only the mind and the body of one individual but minds and bodies between individuals" (p. 349). Whether or not one agrees with his meta-theories, C. Trevarthen $(1977,1979)$ in his pioneeristic works emphasizes, with precise reference to the prelinguistic mother/environment-child exchange, the decisive role played by affect attunement and the significance of the reciprocal affective monitoring in providing the means for human communication and the acquisition of language and of symbolic capacities.

One example only could be sufficient to illustrate it. The children of deaf-mute parents who needed linguistic stimuli in order to learn to speak - inasmuch as language acquisition is a good example of the nature-nurture interaction - were entrusted for a period of time to the linguistic "care" of a video recording. None of them learnt to speak, not only because, as S. Pinker (1995) states, the video recording did not take into consideration the here-and-now of the discourse, or allow to analyze the wish to say more or other than what is said (a pragmatic aspect that is fundamental in verbal communication), but above all because no affect attunement or affect monitoring was possible with the machine.

The argument I am considering, as I anticipated when listing the different issues to be taken into account, also includes the theme of the relationships between thought and language. It would require another paper, and I have included it in the list only as a reminder that in this field also, psychoanalytic theory would benefit from a conceptual update. In a book written in 1998, Language and Thought, as the result of 
an interdisciplinary project, the editors of the volume - Peter Carruthers and Jill Boucher - wrote "we felt that the issue of language and thought had almost dropped from sight in the cognitive sciences in recent decades, and that the time was ripe for a more fine-grained examination of the issues from an interdisciplinary perspective" (p. XIII). The same observation is valid for psychoanalysis; a reflection on the problems relative to the inner language and to the different links between thought and language, between types of representations, etc., would be useful.

\section{GENERAL THEORY OF REPRESENTATION}

The French linguist A. Culioli, who I have already mentioned, has outlined three different levels in the treatment of representation. The first is the level of mental representations, whose conceptualization depends on the discipline involved. The access to this level is obviously not direct. The second level is that of linguistic representations: they carry traces of the activity of the first level, but we cannot hypothesize a bi-univocal relation between the two, due to the fact that representations are heterogeneous. The third level is that of meta-linguistic representations. It is reasonable to presuppose a level of neural activity which precedes and informs the first level and that could be conceived also as heterogeneous if confronted with the others. Freudian psychoanalytical theory introduced a distinction between thing presentation (Dingvorstellung) and word presentation (Wortvorstellung) that cannot be assimilated to the described oppositions. Greatly discussed and criticized from various points of view (e.g. the above mentioned work by Litowitz), but also greatly defended as one of the fundamental concepts of psychoanalysis (e.g. A. Green 1997, 2000, and his theories on tertiary processes), the Freudian concept cannot easily be substituted without impairing some of the nuclear aspects of the theory itself. It could, however, be reformulated: one of these reformulations was made by Green himself and is based on Peirce's theory of the sign (representamen). Following in the wake of his hypotheses, a general theory on representation in psychoanalysis can perhaps be outlined.

It could and should take into account the classification of the interpretants into Immediate, Dynamical and Final that Peirce traced in 1908 within the framework of his general theory on semiosis. Let us recall Peirce's well-known definition on what a sign (Representamen) is, and what, therefore, semiosis is. Peirce says "A Representamen [sign] is the 
subject of a triadic relation with a second, called its Object, and a third, called its Interpretant. This triadic relationship being such that the Representamen determines its interpretant to stand in the same triadic relation to the same object for any Interpretant" (Peirce 1903, p. 285 [1.541]). "Peirce's theorization on semiosis evolves in the form of a dynamic and substitution process. It is a process that includes a very wide range of intra-and-extra-linguistic material to be included in semiosis (feelings, actions, body signals, every class of sign...)" (Canestri 2002, p. 536). However the process must include the final interpretant. The final interpretant is the manner in which the sign tends to represent itself in relation to its object, or the effect that the sign produces in the mind after a sufficient development of thought, even in the mind of the interlocutor when, for example, you ask a question or enounce any kind of utterance. A good illustration is certainly given by Freud's joke (Peirce 1908, p. 232 [8.343]).

In this paper many other perspectives, as well as many other works, authors and lines of research, would have "right of entry". I have chosen only a few samples of what the sciences of language have to offer to psychoanalysis. Of course, I could attempt to carry out the operation in reverse, and I think this would be just as fruitful: I could suggest to the sciences of language what psychoanalysis has to say to them.

\section{REFERENCES}

Amati Mehler, J., Argentieri, S. \& Canestri, J. (1993). The Babel of the Unconscious. Madison, CT: International Universities Press.

Apel, K.O. (1986). Le logos propre au langage humain. Combas: Ed. de l'Eclat 1994.

Austin, J.L. (1962) How to Do Things with Words. Oxford: Clarendon Press.

Bakhtin, M. (1978) Esthétique et théorie du roman. Paris: Gallimard.

Canestri, J. (1991). La passione della lingua originaria nella letteratura e nella psicoanalisi. Il Piccolo Hans 69: 160-186

Canestri, J. (1993). Il soggetto polilogico. In Ri-scritture, ed. Centro Romano di Semiotica. Rome: Eurelle Edizioni.

Canestri, J. (1994a). From internal flux to shared experience. In The Analyst Mind: From Listening to Interpretation. London: The IPA Press, pp. 23-30.

Canestri, J. (1994b). Transformations. Journal of the American Psychoanalytic Association 75: 1079-1092.

Canestri, J. (1999a). Alcune note e un esempio su attività linguistica e psicoanalisi. Psicoanalisi 3(1): 68-82.

Canestri, J. (1999b). Development of affect in bilingual patients. Presented at the $41^{\text {st }}$ International Psychoanalytical Congress, Santiago de Chile. 
Canestri, J. (2000). Notes on linguistic activity and psychoanalysis. In Changing Ideas in a Changing World. The Revolution in Psychoanalysis. London and New York: Karnac Books, pp. 197-205.

Canestri, J. (2001). Ferenczi e l'attività linguistica nell'analisi. In La catastrofe e $i$ suoi simboli. Torino: UTET, pp. 187-197.

Canestri, J. (2002). Trois, le nombre magique: Green avec Peirce. In Penser les limites. Écrits en l'honneur d'André Green. Paris: Delachaux et Niestlé, pp. 531-538.

Carruthers, P. \& Boucher, J., ed. (1998). Language and Thought. Interdisciplinary Themes. Cambridge: Cambridge University Press.

Charaudeau, P. \& Maingueneau, D. (2002). Dictionnaire d'analyse du discours. Paris: Seuil.

Chomsky, N. (1986). Knowledge of Language. Its Nature, Origin and Use. New York: Praeger.

Chomsky, N. (1995). The Minimalist Program. Cambridge, Mass.: MIT Press.

Chomsky, N. (2000). New Horizons in the Study of Language and Mind. Cambridge: Cambridge University Press.

Culioli, A. (1990). Pour une linguistique de l'énontiation. Operations et représentations. Tome I. Paris: Ophrys.

Culioli, A. (2002). Variations sur la linguistique. Paris: Klincksieck.

Danon-Boileau, L. (1987). Le sujet de l'énonciation. Psychanalyse et linguistique. Paris: Ophrys.

Davidson, D. (1984). Inquiries into Truth and Interpretation. Oxford: Oxford University Press.

Diebold, A.R. Jr. (1989). The consequences of early bilingualism in cognitive development and personality formation. In On the Bilingual Person, ed. R. Titone. Ottawa, Ontario: Canadian Society for Italian Studies, pp. 65-92.

Elman, J.L., Bates, E.A., Johnson, M.H., Karmiloff-Smith, A., Parisi, D. \& Plunkett, K. (1996). Rethinking Innateness: A Connectionist Perspective on Development. Cambridge, Mass.: MIT Press.

Fabbro, F. (1999). The Neurolinguistics of Bilingualism. Howe: Psychology Press.

Fónagy, I. (1983). La vive voix. Essais de psycho-phonétique. Paris: Payot.

Freud, S. (1905c). Jokes and their Relation to the Unconscious. S.E. 8.

Gopnik, A. \& Meltzoff, A.N. (1997). Words, Thoughts and Theories. Cambridge: Cambridge University Press.

Gopnik, A. (2000). Theories, language and culture: Whorf without wincing. In Language Acquisition and Conceptual Development, ed. M. Bowerman \& S. Levinson. Cambridge: Cambridge University Press.

Green, A. (1984). Le langage dans la psychanalyse. In Langages: Rencontres psychanalytiques d'Aix-en-Provence. Paris: Les belles lettres, pp. 20-250.

Green, A. (1997). Le langage au sein d'une théorie générale de la représentation. In Pulsions, représentations, langage, ed. M. Pinol-Douriez. Laussanne: Delachaux et Niestlé, pp. 23-66.

Grice, H.P. (1989). Studies in the Way of Words. Cambridge, Mass.: Harvard University Press.

Hagège, C. (1985). L'homme de paroles. Paris: Fayard.

Hagège, C. (1996). L'enfant aux deux langues. Paris: Editions Odile Jacob. 
Kail, M. \& Fayol, M. (2000). L'acquisition du langage. Paris: Presses Universitaires de France.

Karmiloff-Smith, A. (1992). Beyond Modularity: A Developmental Perspective on Cognitive Science. Cambridge, Mass.: MIT Press/Bradford Books.

Kim, K.H.S., Relkin, N.R., Lee, K.M. \& Hirsch, J. (1997). Distinct cortical areas associated with native and second languages. Nature 388: 171-174.

Lacan, J. (1966). Écrits. Paris: Seuil.

Liberman, D. (1983). Linguística, interacción comunicativa y proceso psicoanalítico. Buenos Aires: Ediciones Kargieman.

Lieven, E. (1978). Conversations between mothers and young children: individual differences and their possible implications for the study of language learning. In The Development of Communication, ed. N. Waterson \& C.E. Snow. Chichester: Wiley, pp. 173-187.

Lieven, E. (1978). Turn-taking and pragmatics: two issues in early child language. In Recent Advances in the Psychology of Language: Language Development and Mother-Child Interaction, ed. R.N. Campbell \& P. Smith. New York \& London: Plenum Press.

Lieven, E. (1979). Communication and cooperation in early infancy. A description of primary intersubjectivity. In Before Speech, The Beginning of Human Communication, ed. M. Bullowa. London, pp.321-347.

Litowitz, B.E. \& Litowitz, N. (1977). The influence of linguistic theory on psychoanalysis. A critical, historical survey. International Review of Psychoanalysis 4: 419-448.

Mergenthaler, E. \& Bucci, W. (1999). Linking verbal and non-verbal representations: Computer analysis of referential activity. British Journal of Medical Psychology 72: 339-354.

Pally, R. (1998). Emotional processing: the mind-body connection. In The MindBrain Relationship. London \& New York: Karnac Books, 73-104.

Paradis, M., ed. (1995). Aspects of Bilingual Aphasia. London: Pergamon Press.

Peña, M., Bonatti, L.L., Nespor, M. \& Mehler, J. (2002). Signal-driven computations in speech processing. Science 298: 604-607.

Peirce, C.S. (1903). Degenerate cases. In Collected Papers of Charles Sanders Peirce, ed. C. Hartshorne \& P. Weiss. Vol. 1. Cambridge, Mass.: Harvard University Press 1931, pp. 277-286.

Peirce, C.S. (1908). To Lady Welby. In Collected Papers of Charles Sanders Peirce, ed. C. Hartshorne \& P. Weiss. Vol. 8. Cambridge, Mass.: Harvard University Press 1931, pp. 220-245.

Pinker, S. (1995). The Language Instinct. New York: Harper Perennial.

Searle, J.R. (1969). Speech Acts. London: Cambridge University Press.

Shapiro, T. (1988). Language structure and psychoanalysis. Journal of the American Psychoanalytic Association 36: 339-358.

Shapiro, T. (1991). Words and feelings in the psychoanalytic dialogue. Journal of the American Psychoanalytic Association 39: 321-348.

Snow, C.E. (1986). Speaking with children. In Language Acquisition, ed. P. Fletcher \& M. Garman. Cambridge: Cambridge University Press, pp. 105-132.

Sperber, D. \& Wilson, D. (1986). Relevance. Oxford: Basil Blackwell. 
Trevarthen, C. (1977). Descriptive analyses of infant communication behaviour. In Studies in Mother Infant Interaction, ed. H.R. Schaffer. London: The Loch Symposium, pp. 227-270.

Vinocur de Fischbein, S. (1998). Psicoanálisis y lingüística: contactos e intercambios. Unpublished manuscript. 
